\title{
A 'Judicious' Use of L1 in TL Classroom: Socio-political, Psychological and Functional Dimensions
}

\author{
Muhammad Afzal Awan \\ ELI, King Abdulaziz University \\ PO box 8200, Jeddah 21589 Saudi Arabia \\ E-mail: maawan19@yahoo.ca \\ Muhammad Aslam Sipra (Corresponding Author) \\ JCC, King Abdulaziz University \\ PO Box 80283, Jeddah 21589 Saudi Arabia \\ E-mail: makhan6@kau.edu.sa
}

Doi:10.7575/aiac.alls.v.6n.5p.16

URL: http://dx.doi.org/10.7575/aiac.alls.v.6n.5p.16
Received: 25/04/2015

Accepted: 07/07/2015

\begin{abstract}
In the present study, the authors deliberate that there are no separate boxes in human brain to restrict two different languages to interact with each other. The practice on ground is strongly in favour of allowing L1 to support target language (TL). The paper contests the status quo of maximal input hypothesis and documents enough research in the field of human psychology, code-switching, bilingualism and Socio-Cultural Theory (SCT). The Canadian French Immersion Programme has also been referred to, in the article. The real life teaching and learning experiences have been shared and are connected to the latest theory and research, and it is concluded that this issue has serious sociopolitical and academic dimensions. The study postulates that the extent of L1 to be used is highly context-dependent. A 'judicious' use of L1 should, however, be practiced in target language (TL) class without malign.
\end{abstract}

Keywords: Judicious use, L1, code-switching, socio-political, psychological, functional dimensions

\section{Introduction}

It is not new for the teachers of second and foreign languages to listen to policy statements every now and then to ban L1 as something unholy from their L2 classrooms. Macaro (2009) expresses the similar experience when she had completed some sixteen years of language teaching in 1997. She recollects that she was shocked to hear the policy statements from up to downwards because she had certainly been using small, justified quantities of first language in the classroom. About her own learning experience, she holds that she had used her first language (Italian) to assist her in learning her second language (English) without any apparent damaging effects.

We also want to share a few personal experiences, which, of course, are not our personal whims but very common concerns, almost every second language learner or teacher comes across. We would later try to connect our personal experiences to the theories and practices in the second language education and finally recommend 'a judicious' use of L1 in the target language (TL) classroom for its obvious psychological, socio-political and functional benefits.

In this context, one of the authors shares his personal experiences as a language learner and as a language teacher. The detailed account is given in the next part of the study.

\subsection{Me as a Second Language Learner}

One of the authors narrates that he was born and brought up in Pakistan where he was exposed to Punjabi at home beside some Arabic reading as part of essential religious education, got primary schooling in Urdu which was a kind of foreign language because there was no support available beyond the classroom. He was exposed to English at $6^{\text {th }}$ Grade, at the age of 10 or 11. Again, he was taught English as a foreign language until he finished his high school and went to University where English was solely used as a medium of instruction and that of examinations, however, none of his teachers was a native speaker of English to restrict L1 in his learning experience as such. However, there was a little application of language learnt in the classroom. By the time he went to University, he was almost habitual of learning everything with meaning making i.e. with the help of L1 because code-switching remained at work both within the class and beyond.

I remember once, while I was reading Wordsworth's poetry, a word 'scythe' was troubling me again and again. I consulted a dictionary that had translated it as, 'an instrument used for mowing grass'. It raised further doubts in my mind as I knew many tools that could be used for mowing. Eventually, I looked up the word in bilingual dictionary and only then I conceptualized the exact meanings of the word as there was a picture of scythe in the dictionary too. When I look back, I cannot imagine I could excel in higher education to this level without seeking substantive support from L1. 
He gives further account of his story and states, "I would like to share my learning experience at University in particular, because it was where I came across teachers with different teaching methodologies of their own". In the classes where Krashen's (1982) popular comprehensible input hypothesis was order of the day, I was very often confused and sometimes even lost. "To avoid digression, I would like to quote my experience of learning in two opposing classrooms."

One of my teachers, who had qualification from U.S.A., taught me English Drama who never ever allowed L1 even to peep into his classroom. His teaching was so intensive in the target language (TL) that I used to drown in his class. It was much late at the end of the semester when I revisited the course material and tried to conceptualize it at my own and, hence, passed the exam. I do not have any pleasant memory of my learning experience in that class. On the other hand, I was taught by another professor who had graduated from U.K. and was an icon in the field. He was the one who made an excellent use of L1 in his L2 class. He taught the thickest topics, for example, history of criticism from Aristotle to T. S. Eliot but for his remarkable and apt use of L1, he made the concepts so easy to digest that the students would not need to consult the primary texts the second time. It was in his classroom that every single idea was learnt, enjoyed and taken down by the students. The students never left the classroom until all their questions were answered. Their minds would brim with lofty ideas at the end of every session.

"At the same time, I must also admit that due to the above said learning habit and/or practice, my listening and speaking skills took far longer time to develop". When I see my listening, spoken interaction and spoken production on the CEFR scale, I look back and blame the traditional Grammar Translation Method (GTM), over-use of L1 and the least communicative teaching environment. On the Cummins' (1996) parameter, I developed my "Competence in Academic Language Proficiency (CALP)" first, during my education, and "Basic Interpersonal Communication Skill (BICS) later in my professional life when I experienced greater interaction with the international community during my foreign travelling, living and working in English speaking culture.

\subsection{Me as a Second Language Teacher}

The same author shares his personal experience as a language teacher. Back in 1998, he visited an international language institute in Islamabad for an interview for a teaching position.

"As I entered the building, I found scores of students in the corridors but there was a pin-drop silence as if all of them were dumb". To my curiosity, I inquired and I was told by the staff that the institute had "only English policy".

Similarly, during my stay in Islamabad, one day an undergraduate student visited my residence in the evening and requested me to provide the tutoring service in order for him to pass his English exam. During the introduction, the student revealed that he attended the course I had taught at the university once. Finding his face absolutely unfamiliar, I asked him that I had never seen him in the class; the student gave me an eye opener. He told me that he did come to his class on the first day and spent full one hour in the class where no single word was used in L1 and, thus, he was disappointed, so he thought it better to be away from the class instead of getting further confused.

To further our discussion, we are fairly convinced that there are manifold blessings and miracles of communicative teaching but at the same time, we can hardly compromise on breaking the line of communication, internalization and meaning making. Therefore, striking a good balance of L1 and L2 in the target language classroom is an immediate issue that we wish to further explore in this paper and intend to connect it to the lived experiences as learner as well as teacher on the previous pages.

\section{Blurring boundaries of $L 1$ and $L 2$}

The controversy on allowing or disallowing the use of L1 in the second or foreign language classroom is still a burning question for many reasons. The advantages of L1 may be many but it is not L1 for which we teach L2. Turnbull and Jennifer (2009) assert that the ultimate goal of a second or foreign language classroom remains the learning of the target language. They maintain that practices that undermine this ultimate goal, must be avoided. One strong argument that goes in favour of exclusive target language use is the success of the Canadian French immersion programme. This model of separating L1 and L2 has appealed the educators in many parts of the world even beyond Canada (Krashen1985). The French Immersion Programme is the most studied language programme in the world (Canadian Parents for French 2003). Cummins and Danesi (1990), however, have made their mark in drawing attention of the researchers to the fact that there is much room for improvement in the French immersion programme in Canada.

There is, however, a continuum of perspectives on the target language and first language use (Macaro, 2005). To the one extreme, are the proponents of "virtual position" who see no pedagogical or communicative value in the first language, at all. They believe that if L1 was acquired solely without any external support why L2 should not be learnt alone. Another class of researchers derives inspiration from Krashen's comprehensible input hypothesis. They favour, what has been called the "maximal position". Some of the researchers agree that the target language can sometimes be more easily processed by making reference to the first language, but also caution that over use of first language will unduly reduce learners' exposure to target language input (Atkinson, 1995., Calve, 1993). The inherent danger of this maximal input often results in teacher-centered classroom where the voices are not heard as they should be, as we have mentioned a few incidents from our own learning and teaching experiences. Nevertheless, Macaro (2001) contends that too much focus on teacher target language use with long periods of input modification may result in teacher-fronted lessons in which individual learners may only be speaking the second language for limited amount of time. Cummins (2000) points out that comprehensible input in the second language is indeed the promotion of literal rather than critical 
comprehension. In other words, he opens up a door for bilingual or cross lingual communication in the classroom allowing for critical comprehension to happen.

According to the cognitive processing theory (Ellis, 2005), languages are conceived and processed in the brain much the similar way as other information is stored and processed in terms of working memory and long term memory. Moreover, this theory claims that the first language and the second language are not contained in separate conceptual stores. In simple ways, both first and second language lexical items, in long term memory, are activated when bilingual speaker is trying to process language (Ellis, 2005, Kroll, 1993, \& Libben, 2000). Nevertheless, Swain, Kirkpatrick \& Cummins (2011) endorse that the bilingual brain does not store the two languages in separate 'boxes' which are completely isolated from each other, rather the two languages contact and talk to each other. And this is something what can be sensed by a bilingual learner only. Here lies the vitality of the experiences we have narrated on the previous pages. We want to assert that students are the most important stakeholders of second/foreign language teaching and learning enterprise if we try to avoid to call it an industry.

The researchers are divided on the extent and timing of L1 support in the target language (TL) classroom. However, it has been noted that L1 should be used where complex ideas are to be transferred or dealt with. Krisztina and Robertson (2009) say that where language use is familiar and predicable, it is easier to use target language such as greeting stages of lessons, frequently used commands and announcements, etc.

Practicing teachers justify the use of L1 for many obvious reasons including discipline problems, pressure from learners (Lai, 1996) but in our view, the same is true otherwise. Both parents and students, and the language teaching schools in particular, are very concerned about learning English through English. It is observable in bilingual class that TL speaking teachers have less discipline problems. It may affect the creativity and may break the line of communication, though. Therefore, the issue is not simple rather highly problematic. In this case, we will have to define clearly what we mean by discipline: hushing the voices or allowing the teacher to do the business.

It has been noted that communicative teaching is meant for competent, professional well-trained and confident teachers whereas average teachers prefer to teach TL with as easy support of L1. In other words, it maligns teachers who use L1 on one pretext or another. Carless (2004) makes a reference of a class of Year-1 learners in Hong Kong. She observed a teacher who skillfully succeeded in sustaining the use of TL throughout her teaching by short simple sentences, visual support and by avoiding difficult words. She further elaborates the teachers' careful strategy of giving input, involving the students through oral repetitions and timely questioning. She finally concludes that this production requires commitment, rigorous work and above all confidence which is gained through better training and exposure to pure target language as well as its culture. The teacher in question was educated and trained in the UK. These kind of idealistic pictures are too many in the profession of second/foreign language teaching but the ground realities are much different. It is not just one target for the teachers to meet. They are sandwiched by the "vision" and the "voice", the terms coined by Hayes (1996) and referred to by Tudor (2001). The vision in the curriculum teachers are supposed to deliver and prepare the students for one standardized assessment or the other; whereas 'voice' is the name of those multiple rationalities a teacher is confronted with. These rationalities include student rationalities, institutional and corporate rationalities, sociocultural rationalities and above all teacher's own rationalities which of course, emerge from the context in which teaching and learning happens as asserted by Tudor. Therefore, the issue in hand is not so simple as such.

The following factors both external and internal, are mainly responsible for "to be or not to be":

\begin{tabular}{l|l}
\hline External Factors & $\begin{array}{l}\text { The curriculum, examination, expectation in the school, the attitude of } \\
\text { the head-teacher, colleagues, parents and the political context }\end{array}$ \\
\hline Internal: (teacher-related) & $\begin{array}{l}\text { Professional experience, training, proficiency in TL, self-confidence, } \\
\text { beliefs about and attitude towards the TL. }\end{array}$ \\
\hline Internal: (learner-related) & Age, ability, proficiency level, attitude towards TL \\
\hline Internal: (context-related) & Stage in the lesson and the nature of the task or activity \\
\hline Internal: (use of language) & $\begin{array}{l}\text { The extent to which language use is formulaic or predictable in the } \\
\text { context. }\end{array}$ \\
\hline
\end{tabular}

As pointed out by Krisztina \& Robertson (2009)

\section{Bilingualism}

Perhaps the strongest voice in the body of literature, in favour of bilingualism and multilingualism, is that of Cummins (1990). He sees this issue in a very humanistic and socio- political perspectives. He argues that denying the learners' language and culture is compromising the learners' very self and his or her identity. He is of the view that as educators we are constantly sketching an image not only of our own identities and those we envisage for our student, but also of the society we hope our students will form. Students that have been failed in school predominantly come from communities whose languages, cultures and identities have been distorted and devalued in the wider society. Not surprisingly, students often disengage themselves from school learning under these conditions. His is the strong belief that if school respects the learners' language, it safeguards his or her identity. Cummins dispels the superficial apprehensions of some scholars who think that 'bilingual education could result in at least partial disintegration of the 
United States of America (Dunn 1987). In our view, language is a highly sensitive concern especially in the states where there is great linguistic diversity. If the languages are kept separate, it results in disintegration, mistrust and misunderstandings at both socio-political and socio-cultural levels and history is witness to the fact that many nations suffered serious setbacks. The creation of Pakistan was largely the result of Urdu-Hindi controversy and later, the disintegration of Pakistan in 1971 was an indirect consequence of undermining the Bengali language.

Sipra (2013) investigates into the contribution of the use of bilingualism as an aid in teaching and learning a foreign language and he believes that bilingualism in EFL classroom does not reduce learners' communicative abilities rather, in effect, it can assist in the teaching and learning process.

Without going into the complex details, it seems pertinent to refer to Laurie's narrative (Swain, Cummins \& Kirkpatrick, 2011) that showed stimulating results. She formed two groups of students in her FSL class, and assigned them the task to give a presentation on a complex subject involving critical thinking and analytical reflection. She monitored one group not to use L1 at all whereas allowed the other group to mix up and make use of their L1 freely. Interestingly contend Swain and associates, "and seemingly paradoxically, the oral presentations given the next day in French by the groups who spoke more L1, were judged to be better than those who spoke more French during the preparation time."

There is a growing realization due to political as well as academic reasons to respect the minority languages in linguistically diverse countries. Politically, says Cummins (2001):

We are constantly fighting for a position of power that must be acquired at the expense of someone else, whether this means a position in the job market, economic success of a business or military expansionism of aggressive countries. Power should in fact be collaborative, not coercive. ........Therefore, it is up to us as teachers to nurture our small scale society, the classroom, in such a way that the relationships of power are generously divided for the benefit of all.

Ignoring students' L1 is an indirect way of disempowering them and refusing them to become part of larger society. In the past, many minority students in North America were punished for speaking their first language in school. Thus, these students usually failed to develop adequate literacy skills in their first language and many also experienced academic and emotional difficulty in school.

The ground reality is much different now. The societies and nations are realizing the significance of heritage languages. It is not difficult to witness every now and then, almost in every second/foreign language class that students carry electronic dictionaries in the classrooms despite institutional opposition and make frequent use of them because without meaning-making they cannot survive in the class. Teachers are generally pressed to follow the commands of their employers to restrict themselves as well as their students but code-switching is a technical requirement and a natural phenomenon in bilingual classrooms. No regulations have ever succeeded in checking this thing to happen.

\section{Role of Code-switching and SCT}

Researchers seem convinced that code-switching is a characteristic feature of bilingual talk rather than a deficiency in one or the other of the language ( $\mathrm{Li} 2000$ ). Space does not allow otherwise, one can mention scores of functions that code-switching performs naturally. When we talk of code-switching, it brings along Vygotsky and his descendent researchers who believe that language learning is deeply embedded in social and cultural experiences. Socio-cultural theory suggests that inner voice and private speech are essential contributors to the way we think and act, and that they are almost performed in the first language (Brooks \& Donoto, 1994). The concept of scaffolding in language learning was developed by Vygotsky's followers posthumously. Scaffolding still holds central role in the teaching and learning theories and practices. Laurie's narrative mentioned above is the best example of code-switching and SCT and its subsequent principle of scaffolding in action. Fuller (2009) acknowledges that many researchers have grown dissatisfied with the neglect of the social dimension of second language acquisition. It is heartening to note that research is even taking newer shapes in this field with the theory of ecological learning propounded by Van Lier (2004). He is of the view that every language teacher and researcher must read at the earliest to gauge how deeply embedded and supportive are philosophy, psychology, anthropology and linguistics in the process of language learning. He puts language in the heart of all what education is and or, should be.

\section{Conclusion}

It is evident from the discussion above that the issue of L1 in L2 classroom must not be overlooked. Neither the employers who insist on maximal input principle are absolutely wrong nor can the ground realities be denied. The purpose by all means is not to maintain the status quo but to establish a productive and mutual co-existence for promotion of target language (TL) with an equal respect to L1 or L1s. As far as the optimal use of TL, one can simply say it depends on the essentially dynamic nature of the teaching context. It is high time to begin envisioning that learners are not as ineffective and imperfect monolingual speakers of the target language TL, but as aspiring bilinguals (Turnbull \& Jennifer, 2009). It is also a reality on ground, they establish that learners can never become perfect monolingual speakers of the target language (TL), and educators who take that as their goal cannot help but fail. Therefore, the success of all the stake-holders, students, teachers, parents, policy-makers, minority groups in the states and states themselves, lies in acknowledging the 'judicious' use of L1 in the target language (TL) classroom without malign. This practice is fairly informed by research in psychology and affirms numerous metacognitive benefits on the 
one hand and may pave the way for democracy and social justice in the long run. The preservation of minority languages will be a value-added gift of this move as every student of linguistics is concerned that $90 \%$ of today's languages are at the risk of going extinct in the next 50 years or so.

\section{References}

Atkinson, D. (1995). English only in the classroom: Why do we do it? The Polish Teacher Trainer. Retrieved from http://ettc.uwb.edu.pl/strony/ptt/feb95/8.html.

Brooks, F. \& Donato, R. (1994). Vygotskian approaches to understanding foreign language learner discourse during communicative talks. Hispania, 77, 262-274

Calvé, P. (1993). Pour enseigner le français . . en français. Canadian Modern Language Review 50 (1), 15-28.

Carless, D. R. (2004). A contextualised examination of target language use in the primary school foreign language classroom. Australian Review of Applied Linguistics. 27, 104-119

Cummin, J. (1996). Negotiating identities: Education for empowerment in diverse society. Ontario: California Association for Bilingual Education

Cummins, J. \& Danesi, M. (1990). Heritage languages: The development and denial of Canada's linguistic resources. Toronto: Our Schools/Our Selves and Garamond Press.

Cummins, J. (2000). Language, power, and pedagogy: Bilingual children in the crossfire. Clevedon: Multilingual Matters.

Cummins, J. (2001). Negotiating identities: Education for empowerment in a diverse society (2nd ed.). Los Angeles:

California Association for Bilingual Education.

Dunn, L.M. (1987). Bilingual Hispanic children on the US mainland: a review of research on their cognitive, linguistic and scholastic development. Circle Pines, MN: American Guidance Service.

Ellis, N.C. (2005). At the interface: Dynamic interactions of explicit and implicit language knowledge. Studies in

Second Language Acquisition 27, 305-352.

Ellis, R. (2008). The study of second language acquisition. Oxford: Oxford University Press

Fuller, J. M. (2009). How Bilingual Children Talk: Strategic Code-switching Among Children in Dual Language Programs. First Language Use in Second and Foreign Language Learning. Clevedon: Multilingual Matters.

Hayes, J. R. (1996). A new framework for understanding cognition and affect in writing. In C. M. Levy \& S.

Ransdell (Eds.). The science of writing: Theories, methods, individual differences, and applications (pp. 1-

27). Mahwah, NJ: Lawrence Erlbaum.

Krashen, S. D. (1982). Principles and practice in second language education. New York: Pergamon

Krashen, S. D. (1985). The input hypothesis: Issues and applications. London: Longman

Krisztina, N. \& Robertson, D. (2009). First language use in second and foreign language learning. Bristol: Multilingual Matters

Kroll, J. (1993). A ssessing conceptual representations. In R. Schreuder and B. Weltens (eds) The Bilingual Lexicon (pp. 249-277). Amesterdam/Philadelphia: John Benjamins

Li, W. (2000). Dimensions in Bilingualism. In Li, W. (ed.) Bilingualism Reader, London: Routledge.

Lai, M. L. (1996). Using the L1 sensibly in English language classrooms. Journal of Primary Education, 6 (1-2): 91-99

Libben, G. (2000). Representation and processing in the second language lexicon: The homogeneity hypothesis. In Archibald, J. (ed.) Second Language Acquisition and Linguistic Theory. Oxford: Blackwell

Macaro, E. (2001) Analysing student teachers' code-switching in foreign language classrooms: Theories and decision making. The Modern Language Journal 85 (4), 531-548.

Macaro, E. (2005). Code-switching in the L2 classroom: A communication and learning strategy. In E. Llurda (ed.)

Non-Native Language Teachers: Perceptions, Challenges and Contributions to the Profession (pp. 63-84). New York: Springer.

Macaro, E. (2009). Teacher use of code-switching in the second language classroom: Exploring optimal use. In M. Turnbull, and J. Dailey O'Cain (ed) First language use in second and foreign language learning (pp. 35-49). Bristol: Multilingual Matters

Mac Namee, T. \& White, H. (1985). Heritage language in the preschool. Language and Society, 15(Winter), $20-23$. Sipra, M. A. (2013). Contribution of bilingualism in language teaching. English Language Teaching. 6 (1), 56 - 66 http://dx.doi.org/10.5539/elt.v6n1p56

Swain, M., Kirkpatrick, A., \& Cummins, J. (2011). How to have a guilt-free life using Cantonese in the English class: A handbook for the English language teacher in Hong Kong. Hong Kong: Research Centre into Language Acquisition and Education in Multilingual Societies, Hong Kong Institute of Education. 
Tudor, I. (2001). The dynamics of teaching and learning. In Tudor, I., The Dynamics of the language classroom. Cambridge: Cambridge University Press

Turnbull, M. S. \& Macmillan, B. (2009). Teachers' use of the first language in French immersion: Revisiting a core principle. In Turbull, M.S. \& Jennifer, D. First language use in second and foreign language learning. Bristol: Multilingual Matters

Van Lier, L. (2004). The Ecology and Semiotics of Language Learning: A sociocultural perspective. Dordrecht: Kalwar Academic Publishers. 